\title{
KAHALE CARRILLO, Djamil Tony, Planes de formación en igualdad de género, Thomson Reuters-Aranzadi, Cizur Menor (Navarra), $1^{\mathrm{a}}$ ed., 2021, 361 páginas
}

\author{
JOSÉ MARÍA URIS LLORET \\ Doctor en Derecho \\ Universidad de Murcia (España) \\ joseull@outlook.es
}

https://orcid.org/0000-0002-7936-1567

La obra que nos presenta Djamil Tony Kahale Carrillo con el título "Planes de Formación en Igualdad de Género” es un manual perteneciente a la colección Estudios- Aranzadi de la editorial Thomson Reuters-Aranzadi.

El libro aborda con gran rigor y profundidad una materia tan compleja como es la igualdad de género, con la finalidad, entre otras, de formar a educadores y educadoras, personal docente y estudiantes, objetivo que, a nuestro juicio, logra de forma significativa. Pero también es de gran utilidad para todas las personas que tengan interés en dicha materia, siendo una obra de referencia en uno de los retos más importantes que tiene la sociedad en la actualidad: lograr la igualdad de todos los integrantes de la población. Porque, sin ninguna duda, alcanzar la igualdad entre mujeres y hombres será el primer eslabón para avanzar hacia una sociedad con menos desigualdades.

El conocimiento que muestra el doctor Kahale Carrillo sobre los temas que trata en el manual es fruto de su extensa labor de investigación, en la que en varias ocasiones ha aportado trabajos de indudable interés en las cuestiones que afectan a la igualdad de 
mujeres y hombres. Nos acercamos, en primer lugar, al más reciente, publicado el pasado mes de abril: "La música y la igualdad a través de sus letras", un proyecto muy innovador que nos muestra que "la música, a través de las letras de sus canciones, es una herramienta didáctica e idónea para trabajar los diferentes tipos de discriminación (igualdad de género, LGTBI, racismo, discapacidad, entre otros) con el alumnado en el aula". Pero no es este el único trabajo innovador que ha llevado a cabo, en el año 2014 publicó "El impacto de las apps en la violencia de género" que recibió el XVII Premio Leonor de Guzmán, otorgado por la Cátedra de Estudios de las Mujeres.

Además de las citadas en el párrafo anterior, también queremos mencionar, entre otras, "El derecho de asilo frente a la violencia de género" que recibió el primer premio de la Fundación Aequitas en el año 2009, "La responsabilidad social de género" que recibió el V Premio a la investigación en ética empresarial en el año 2012 y "La violencia de género en el contenido de los estatutos de autonomía". Asimismo, también citamos las siguientes obras: "La protección jurídica del acoso laboral" y "El acoso laboral (mobbing): tratamiento jurídico y preventivo", por tratar en el capítulo siete el acoso laboral, sexual y por razón de sexo.

Una vez presentado el libro y el autor, consideramos que debemos detenernos brevemente en el prólogo y en la presentación, porque nos acercan de forma muy precisa al contenido de la obra y nos sirven de guía para iniciar su lectura. La señora García Mendez, Directora General de Mujer y Diversidad de la Comunidad Autónoma de la Región de Murcia, señala en el prólogo que vivimos en la sociedad de la información y el conocimiento, tenemos acceso a un número ingente de datos, como nunca hubieran imaginado generaciones anteriores, pero también estamos expuestos a una información que no es fiable y que nos puede confundir, por lo que es preciso, como señala la autora citada anteriormente, que los datos que recibimos estén organizados, que tengan un orden que les dé sentido.

Y, en este aspecto, consideramos que la obra que estamos examinando puede ser básica para las personas que inician sus estudios sobre esta materia, al presentar de una forma tan didáctica la información. Además, es de utilidad para las personas que quieran ampliar su conocimiento sobre la temática que estamos tratando, porque la bibliografía, las lecturas que recomienda, las leyes que cita, las declaraciones de organismos institucionales y las sentencias que aporta son un punto de partida de un trabajo de investigación en género e igualdad, dado que dibuja un horizonte muy amplio.

Asimismo, la señora Lucas Bermúdez, Directora de la Unidad de Igualdad de la Universidad Politécnica de Cartagena, al hacer la presentación de la obra, expone que el autor trata conceptos fundamentales como la teoría feminista, la mujer y el mercado de trabajo, el acoso sexual y laboral, la violencia de género, la conciliación de la vida laboral y personal o los planes de igualdad que son esenciales en todos los ámbitos sociales.

El nivel tan alto del conjunto de la obra del doctor Kahale Carrillo conlleva que el realizar un resumen objetivo y analítico de la monografía que estamos examinando en la presente 
recensión, por una parte, sea una tarea grata por los conocimientos que nos aporta su estudio, pero, por otra parte, es de una gran responsabilidad, porque queremos trasladar en nuestra exposición el interés que nos ha suscitado dicha monografía.

Antes de entrar en la descripción del contenido, entendemos que debemos observar que la igualdad de género es un tema muy complejo debido a la discriminación que han sufrido y aún sufren las mujeres en todas las áreas. Acercarse a hechos tan críticos, entre otros, como la violencia que se ejerce sobre ellas es una labor muy difícil, si además esa monografía va dirigida a formar en género e igualdad a una sociedad multicultural, donde conviven personas que proceden de distintos puntos geográficos del planeta que, como es evidente, han tenido experiencias muy distintas y pueden tener un punto de vista diferente. La forma tan clara en que se exponen los conceptos, pese a la complejidad que entrañan, así como la amplia información que se aporta, facilita la comprensión de su contenido a una sociedad global como es la nuestra.

Asimismo, el autor también tiene presente la descentralización del estado español y las competencias que en materia legislativa tienen las comunidades autónomas, haciendo referencia a las normativas autonómicas más relevantes, destacando, por ejemplo, en relación a la definición de la violencia de género a la Ley canaria 16/2003, de 8 de abril, de Prevención y Protección Integral de las Mujeres contra la Violencia de Género y a la Ley 4/2007, de 22 de marzo, de Prevención y Protección Integral a las Mujeres Víctimas de Violencia en Aragón.

La obra se estructura en diez capítulos, ordenados con muy buen criterio, y todos siguen un mismo esquema: en el primer punto se expone el objeto de estudio de ese apartado y el análisis que se va a realizar, desarrollando después en varios epígrafes el tema propuesto, continua con unas actividades voluntarias y preguntas de autocomprobación, aportando también en el punto siguiente las respuestas para que se pueda evaluar el conocimiento adquirido y, en el último enunciado, apunta la bibliografía recomendada y consultada. Cierra el libro un glosario que contiene todas las palabras utilizadas. Asimismo, la obra se presenta en formato dúo (papel+eBook), que nos proporciona todas las ventajas del libro electrónico.

Estamos viviendo y hemos vivido durante siglos en un modelo de sociedad anacrónico que dejaba a las personas del sexo femenino en un segundo lugar en todos los ámbitos, para seguir avanzando hacia un modelo de sociedad en que todas las personas tengan igualdad de oportunidades, es necesaria la formación en género e igualdad en diversos espacios, principalmente en el educativo y laboral, y dar un apoyo significativo a la labor de investigación. En este sentido, la obra que estamos analizando es de suma utilidad para todas las personas que estén interesadas en conocer las circunstancias que acontecen en la igualdad entre hombres y mujeres.

Partiendo de ese punto, juzgamos que los tres primeros capítulos son básicos para acceder a las cuestiones de género e igualdad, independientemente del fin que persigan las personas que se acercan a la materia que estamos examinando. Porque, en el primer 
capítulo, a modo de introducción se exponen los conceptos fundamentales, con el objetivo de que la lectora y el lector se familiaricen con esos términos que son básicos en la formación en igualdad de género. Conocer, entre otras, lo que significa las expresiones: perspectiva de género, discriminación indirecta, discriminación por asociación, es necesario para toda persona que quiera adentrarse en estudios relacionados con la igualdad entre mujeres y hombres, y usualmente hay que buscarlos por distintas publicaciones, por lo que consideramos que de la forma en cómo se desarrolla el primer apartado del libro facilita el conocimiento de dichos conceptos.

En el segundo capítulo "se hace un recorrido de las políticas de igualdad desde el ámbito internacional, pasando por el comunitario hasta llegar por lo regulado en el ordenamiento jurídico español" (p. 64). El epígrafe se inicia con unos apartados sobre "La igualdad entre mujeres y hombres" y "Las políticas de igualdad de oportunidades entre mujeres y hombres" para a continuación reseñar los datos más importantes de las Conferencias Mundiales sobre la Mujer".

Aunque aún estamos muy lejos de lograr la igualdad de género, se han realizado importantes avances en los últimos siglos gracias a la lucha y el tesón de muchas mujeres que de forma ejemplar han trabajado para superar un orden androcéntrico. El tercer capítulo nos traslada a ese esfuerzo de millones de mujeres, haciendo "un recorrido de las teorías y movimientos de mujeres a través de la historia" (p. 93). El "punto de partida surge con el origen y la definición de feminismo" (p. 93), para en los apartados siguientes describirnos las olas del feminismo en la historia, el feminismo socialista, los movimientos feministas en nuestro país y las circunstancias en que se han desenvuelto desde principios del siglo $\mathrm{XX}$.

Es difícil, por lo menos para quien escribe estas líneas, tratar ciertos asuntos desde un punto de vista material, menos cuando se trata de un tema tan enraizado en la vida de las personas como es la igualdad entre mujeres y hombres, pero es indudable que, para conquistar espacios de libertad, tiene un peso importante la incorporación al mercado de trabajo. Así tenemos que, desde la década de los sesenta del siglo pasado que se incorporaron las mujeres de forma más numerosa al trabajo remunerado, han tenido una presencia más importante en la sociedad, llegando a ámbitos profesionales donde siempre habían sido excluidas, como por ejemplo la judicatura. La primera jueza española tomó posesión de su juzgado en 1972, casi cincuenta años después, según el último informe de Estructura demográfica de la Carrera Judicial, el 54,85 por ciento del total son mujeres.

La importancia que tiene para la igualdad de género el trabajo remunerado en el contenido de la obra lo podemos observar al dedicar cuatro capítulos a esa temática, partiendo del capítulo cuarto donde se expone la situación de las mujeres en el mercado laboral, así como la discriminación que sufre en dicho ámbito con el objetivo de expulsarla de los centros productivos o dejarla en una situación subalterna. Para posteriormente hacer un análisis de la evolución del mercado de trabajo, finalizando con el apartado de "La mujer en la dirección de la empresa" en la que afirma que "a pesar de poseer una mayor formación y, generalmente, las características apropiadas para desempeñar la dirección 
de la empresa, cuenta con la tasa más elevada de desempleo, ocupa trabajos a tiempo parcial, obtiene salarios inferiores al hombre y tiene menos oportunidades de promoción profesional hacia puestos de trabajo que implican poder y toma de decisiones" (p. 140).

Entre los obstáculos que impiden lograr el objetivo de una sociedad igualitaria, uno de los más importantes es que la atención a la familia y el hogar no sea asumida en mayor medida por las mujeres Consciente de esa realidad, el autor de forma exhaustiva en el capítulo cinco analiza las medidas para conciliar la vida personal, laboral y familiar, en donde se exponen las reducciones del tiempo de trabajo, los permisos, las excedencias, la conciliación del trabajo con la maternidad y la paternidad y los riesgos laborales durante el embarazo y la lactancia natural.

En el capítulo sexto se analiza la igualdad retributiva entre mujeres y hombres. Se emprende con la prestación salarial para tratar posteriormente la igualdad salarial, el principio de transparencia retributiva y los instrumentos de transparencia retributiva, tales como el registro retributivo y la auditoría retributiva que "tiene por objeto obtener la información necesaria para comprobar si el sistema retributivo de la empresa, de manera transversal y completa, cumple con la aplicación efectiva del principio de igualdad entre mujeres y hombres en materia de retribución” (p. 220).

El varón, hasta hace aproximadamente sesenta años, ostentaba el espacio laboral en exclusividad y un número importante de ellos percibió la llegada de la mujer a ese ámbito como una amenaza, utilizando la violencia para intimidarla o expulsarla de los centros de trabajo. En el manual se exponen con exactitud las conductas incívicas que se utilizan para agredir a las trabajadoras, tales como el acoso laboral, el sexual y por razón de sexo, matizando, para un mejor conocimiento de esos comportamientos violentos, las diferencias que existen entre esos actos hostiles.

En el capítulo séptimo se examina la violencia más grave que sufren las mujeres, estudiando la violencia de género y los conceptos afines, el derecho a la información y asistencia social integral y jurídica gratuita que tienen las víctimas, así como los derechos laborales y prestaciones de la seguridad social.

"El plan de igualdad es una herramienta estratégica que comprende una serie de acciones para integrar la igualdad entre mujeres y hombres en la gestión de una organización laboral, que fija los concretos objetivos de igualdad a alcanzar, las estrategias y prácticas a adoptar para su consecución; así como el establecimiento de sistemas eficaces de seguimiento y evaluación de los objetivos fijados. Por tanto, el plan de igualdad comporta, en esencia, la idea de unidad, estructura y coherencia interna" (pp. 292-293). De la definición que realiza el autor de dicha herramienta que persigue la igualdad de trato entre hombres y mujeres en los centros de trabajo podemos deducir la importancia que tiene conocer el proceso de implantación de los planes de igualdad en las organizaciones, que se recoge ampliamente en el capítulo noveno. 
Para finalizar, el último capítulo estudia el distintivo empresarial en materia de igualdad, "que es un reconocimiento que la Administración pública otorga a todas aquellas empresas que destaquen por las medidas que desarrollan para garantizar la igualdad de trato y de oportunidades entre trabajadores y trabajadoras, que podrá ser utilizado en el tráfico comercial de la empresa y con fines publicitarios" (p. 325). Valoramos positivamente que se dedique un capítulo a dicho distintivo, la divulgación de ese reconocimiento facilitará la igualdad de género en los centros de trabajo.

Por todo lo expuesto, consideramos que estamos ante una obra de referencia a tener muy en cuenta en la formación de igualdad de género. Su consulta será necesaria, tanto para las personas que inicien dicho estudio, así como para las que ya han avanzado en la materia citada, porque el análisis que realiza y la información que ofrece son de suma utilidad para ampliar su conocimiento. 